\title{
Implementasi Authorized Service Center Management System Berbasis Web Di CV Next Solution
}

\author{
Adi Rahmansyah ${ }^{1}$, Sari Susanti ${ }^{2}$ \\ ${ }^{1,2}$ Universitas Adhirajasa Reswara Sanjaya \\ e-mail: 1dirahmansyah@gmail.com, ${ }^{2}$ sarisusanti@ars.ac.id

\begin{tabular}{ccc} 
Diterima & Direvisi & Disetujui \\
$15-11-2021$ & $16-11-2021$ & $30-11-2021$ \\
\hline
\end{tabular}

\begin{abstract}
Abstrak - Pengguna laptop yang semakin banyak membuat jasa-jasa perbaikan atau reparasi laptop yang marak berkembang. Sekian banyaknya laptop yang dititipkan pada service center untuk diperbaiki. CV Next Solution merupakan salah satu service center resmi dari Lenovo yang terletak di Kota Bandung. Seiring berjalannya waktu, jumlah kunjungan ke tempat service tersebut semakin banyak, hal ini membuat admin service kewalahan dalam menangani pendataan barang service dan pelanggannya.Prosedur pendataan dan pelacakan yang digunakan saat ini masih belum saling terintegrasi antara data yang terdapat pada admin service dengan teknisi. Solusi yang diajukan adalah dengan menerapkan authorized service center management system berbassis website dengan Laravel sebagai frameworknya dan MySQL sebagai databasenya yang terintegrasi di CV Next Solution. Waterfall merupakan metode yang digunakan untuk membangun sistem ini yang didalamnya mencakup mulaii dari analisa selanjutnya ke tahap desain dan yang terakhir tahap menyusun kode dan uji coba.. Hasilnya sistem informasi yang telah dibuat memudahkan teknisi mengecek history diagnosa perbaikan, serta mempercepat dan mengurangi beban kerja admin service. Sistem ini mampu mengintegrasikan pengelolaan data service yang sesuai dengan keinginan owner maupun kebutuhan pemrosesan data service di CV Next Solution.
\end{abstract}

Kata kunci: Sistem Manajemen Service, Pemrograman Website, Framework Laravel.

\begin{abstract}
More and more laptop users make laptop repair or repair services that are growing. So many laptops are entrusted to the service center for repair. CV Next Solution is one of the official service centers from located in the Bandung city. As time goes by, the number of visits to the service area is increasing, this makes the service admin overwhelmed in handling data collection of service goods and customers. The data collection and tracking procedures used today are still not mutually integrated between the data contained in the service admin and technicians. The proposed solution is to implement an authorized service center management system based on a website with Laravel as the framework and MySQL as the integrated database in CV Next Solution. Waterfall is the method used to build this system which includes starting from the next analysis to the design stage and finally the stage of compiling code and testing. As a result, the information system that has been created makes it easier for technicians to check the history of repair diagnoses, as well as speed up and reduce the admin workload. service. This system is able to integrate data service management in accordance with the owner's wishes and data service processing needs at CV Next Solution.
\end{abstract}

Keywords: Service Management System, Website Programing, Laravel Framework.

\section{PENDAHULUAN}

Laptop merupakan perangkat komputer yang bisa dengan mudah dibawa kemanapun. Mobilitas yang canggih bagi seorang pengguna sering kali menjadi alasan pokok untuk memiliki sebuah laptop. Bagi sebagian orang yang banyak menghabiskan waktu di luar kantor, mempunyai laptop adalah suatu kewajiban. Tentunya tidak ada yang ingin laptopnya rusak, tetapi sering kali dikarenakan sebab khusus atau sedang dalam kondisi buruk memperoleh produk yang rusak lebih awal, serta tidak diketahui sebelumnya. Jika kerusakan laptop cukup menyulitkan dan tidak bisa diperiki sendiri, maka membawanya ke service center adalah solusi terbaik dan aman bagi pengguna (Yudhanto \& Sulandari, 2018).

Ternyata pandemi Coronavirus Disease 2019 tidak membuat pasar laptop merosot. Pasar laptop secara global meningkat sebesar 12,7 persen tahun-ke-tahun (YoY) selama Q3 2020. Perkembangan laptop pada Q3 2020 tercatat hingga 79,2 juta unit, dalam 10 tahun terakhir, itu merupakan pertumbuhan terpesat di pasaran. Salah satu faktor yang mendorong meningkatnya pemebelian Personal Computer dalam jumlah yang banyak selama 
pandemi adalah karena adanya kebijakan kerja dari rumah. Mobile News dalam pemberitaannya, HP telah diungguli oleh Lenovo sebagai posisi teratas dengan segmen pasar sebesar 24,3 persen. Pada Q3 dan dengan pengiriman sekitar 19,2 juta unit, Lenovo sebagai vendor mengalami peningkatan sebesar 11,4 persen YoY (CNN, 2020).

Lanovo menyediakan layanan service untuk semua produk laptopnya yang dipasarkan kepada pelanggan. CV Next Solution merupakan salah satu service center resmi dari Lenovo yang terletak di Kota Bandung. Pusat layanan Lenovo hadir bertujuan untuk memudahkan para pelanggan di Bandung dan sekitarnya. Kemudian sebagai bukti komitmen Lenovo kepada pelanggan agar agar mendapatkan dukungan dan layanan yang di butuhkan oleh pelanggan. Keberadaan pusat layanan ini menjadi salah satu bukti komitmen Lenovo dalam menyediakan dukungan dan layan yang terabaik, serta memegang teguh loyalitas perusahaan terhadap para pelenggannya yang berada di sekitar wilayah Bandung.

Sejak kehadiran service center resmi Lenovo di Kota Bandung, perusahan yang mempunyai layanan reparasi laptop ini mulai banyak dikunjungi oleh para pelanggan. Mereka berkunjung untuk memperbaiki laptopnya yang mengalami kerusakan ataupun kendala yang tidak bisa diatasinya. Seiring berjalannya waktu, jumlah kunjungan semakin banyak yang membuat admin service kewalahan dalam menangani pendataan barang service dan pelanggan yang memakan waktu cukup lama. Dan juga, teknisi kesulitan dalam melakukan pengecekan history diagnosa perbaikan laptop sebelumnya. Penyebabnya tidak lain karena prosedur pencatatan data dan pencarian data yang digunakan sekarang ini masih belum saling terintegrasi antara data yang terdapat pada admin service dengan teknisi.

Beberapa prosedur pendataan service barang elektronik dapat diintegrasikan menggunakan sistem berbasis website seperti perancangan aplikasi pengolahan data service laptop pada Syifa Komputer di Kuala Kapuas. Sistem informasi pengolahan data service laptop ini menjadi solusi dalam menyimpan data yang jauh lebih besar dan teratur, memudahkan mencari data, serta beban kerja pegawai menjadi lebih ringan yang berpengaruh terhadap kinerjanya (Shalludin, 2019). Selanjutnya CV Bismani Solusindo di Jakarta yang menerapkan sistem informasi pelayanan jasa service laptop. Sistem informasi yang CV Bismani terapkan agar dapat memudahkan proses pencatatan data, resiko kesalahan dalam memasukan data dapat dikurangi, serta mengetahui laporan penerimaan dan pembayaran (Luthfi, 2020).

Suatu sistem informasi berbasis website dapat memperluas jangkuan penyebaran informasi produk dan membantu memudahkan perusahaan (Ibrahim \& Susanti, 2021). Pada penelitian ini diperoleh permasalahan-permasalahan yang dapat dirumuskan dalam mencari solusi untuk mempercepat dan mengurangi beban kerja admin service dalam melakukan pendataan barang service dan pelanggan. Kemudian diperlukan adanya sistem yang terintegrasi yang memudahkan teknisi dalam melakukan pengecekan history diagnosa perbaikan laptop sebelumnya. Kebutuhan-kebutuhan ini dapat diakomodasi dengan sistem informasi berbasis website menggunakan framework Laravel yang dapat diandalkan dalam membantu suatu perusahaan dalam kalkulasi pembayaran gaji karyawan dalam waktu yang bersamaan (Junaedi et al., 2020). Sedangkan solusi yang diajukan bagi permasalahan pada penelitian ini adalah dengan menerapkan authorized service center management system menggunakan pemrograman website yang terintegrasi di CV Next Solution untuk pendataan dan pengecekan history dari service laptop.

\section{METODE PENELITIAN}

\subsection{Metodologi Pengumpulan Data}

Proses pengumpulan data penelitian ini, penulis melakukan tiga metodologi pengumpulan data yaitu pengamatan objek, wawancara, dan studi literatur. Terdapat beberapa metode pengumpulan data untuk kebutuhan penyusunan penelitian ini dapat diterangkan (Wiguna et al., 2020), sebagai berikut:

1. Pengamatan objek

Mengamati, memmahami, dipelajari segala aspeknya, serta dicatat langsung berkenaan dengan sistem pencatatan service laptop sampai dengan dibuatnya laporan, semua itu dilakukan dalam pengamatan. data yang dihasilkan cukup akurat dengan metode seperti ini.

2. Dengar pendapat atau tanya jawab

penulis melakukan diskusi dan tanya jawab terhadap teknisi dan bagian administrasi yang berhubungan dengan sistem layanan service laptop secara langsung agar data yang didapatkan lengkap. Selain itu, dilakukan juga wawancar dengan pemilik yang sekaligus direktur dari CV Next Solution tentang kebutuhan sistem pendataan yang diinginkan.

3. Referensi

Mengumpulkan teori-teori berdasarkan sumber yang akurat dari buku dan jurnal yang dapat membantu dalam penyusunan penelitian beserta sistem layanan service yang akan dibuat.

\subsection{Model Pengembangan Sistem}

Terdapat penelitian yang menggunakan model Waterfall pada pembuatan suatu sistem informasi berbasis website (Susanti et al., 2017). Pengembangan sistem yang akan digunakan penulis yaitu model waterfall dengan metode SDLC (System Development Lif-Cycle). SDLC yaitu prosedur dalam mengubah atau mengembangkan sebuahs software 
dengan mempergunakan metode dan model yang sebelumnya untuk dikembangkan menjadi sistem yang baru..

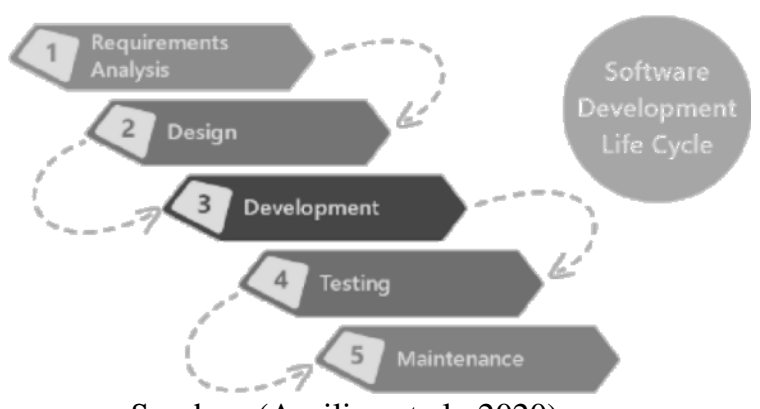

Sumber: (Aprilian et al., 2020)

Gambar 1. Model Pengembangan Sistem

Pada Gambar 1 pendekatan garis hidup sistem secara berurutan yang ada di metode waterfall (Wiguna \& Alawiyah, 2019), yaitu:

1. Analisis Kebutuhan

Diperlukannya komunikasi untuk memahami sistem informasi yang diinginkan oleh CV Next Solution serta batasannya. Pihak perusahaan mendapatkan data yang di butuhkan dari infromasi yang telah dianalisa.

2. Desain Sistem

Membantu dalam mendesain sistem layanan service laptop yang akan dibuat serta membantu dalam mendeskripsikan rangkaian keseluruhan sistem menggunakan diagram-diagram UML dan juga ERD.

3. Penerapan

Untuk pertama kalinya sistem dibuat di sebuah program kecil yang didefinisikan sebagai unit yang dipecah menjadi Model, View, dan Controller yang menyatu pada tingkat selanjutnya. Unit-unit yang dikembangkan menggunakan framework Laravel.

4. Tes dan Integrasi

Seluruh unit yang dikembangkan dalam tahap implementasi diintegrasikan kedalam sistem setelah pengujian pada masing-masing unit. Setelah integrasi seluruh sistem diuji untuk mengecek setiap kegagalan maupun kesalahan menggunakan black box testing.

5. Operasi dan Pemeliharaan

Sistem layanan service laptop yang telah selesai dibuat, difungsikan dan dipelihara. Perbaikan kesalahan pada langkah yang sebelumnya tidak ditemukan tercakup di pemeliharaan. Perbaikan penerapan unit sistem serta peningkatan layanan sistem, sebagai kebutuhan baru.

\section{HASIL DAN PEMBAHASAN}

\subsection{Analisis Kebutuhan}

A. Tampilan Admin Service:

1. Login dapat dilakukan oleh Admin service.
2. Mengelola data customer dapat dilakukan oleh Admin Service.

3. Mendata service dapat dilakukan oleh Admin.

4. Melihat laporan dapat dilakukan oleh Admin Service.

5. Mengubah profile dapat dilakukan oleh Admin Service.

6. Logout dapat dilakukan oleh Admin Servicet.

B. Tampilan Teknisi:

1. Login dapat dilakukan oleh Teknisi.

2. Memproses service (kelola symptom, perbaikan unit) dapat dilakukan oleh Teknisi.

3. Merubah profile dapat dilakukan oleh Teknisi.

4. Logout dapat dilakukan oleh Teknisi.

C. Tampilan Owner:

1. Login dapat dilakukan oleh Owner.

2. Mengelola pengguna sistem dapat dilakukan oleh Owner.

3. Melihat laporan service dapat dilakukan oleh Owner.

4. Merubah profile dapat dilakukan oleh Owner.

5. Logout dapat dilakukan oleh Owner.

\subsection{Desain Sistem}

Desain sistem membantu dalam mendesain sistem layanan service laptop yang akan dibuat serta membantu dalam mendeskripsikan rangkaian sistem secara keseluruhan menggunakan diagram-diagram UML dan juga ERD.

\section{A. Use Case Diagram}

Pembuatan use case diagram antara admin service dan owner dengan sistem manjemen service dapat dilihat gambarnya pada Gambar 2.

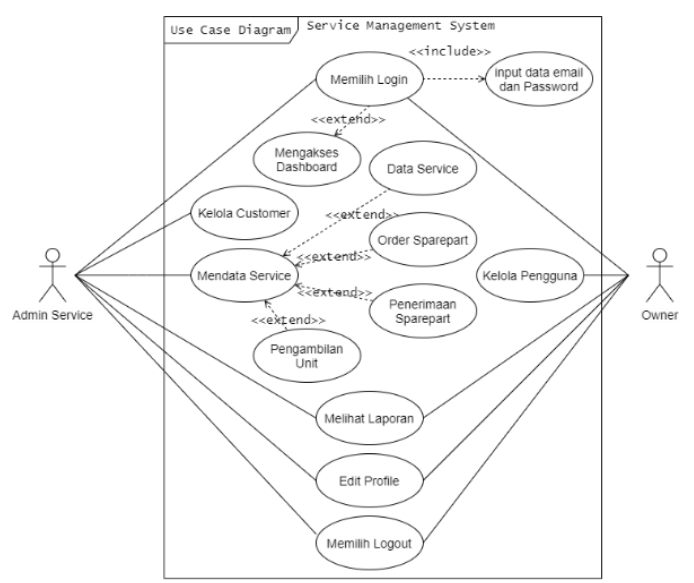

Gambar 2. Use Case Diagram Proses Pendataan

Gambar 2 menjelaskan use case diagram proses pendataan yang dilakukan oleh admin service dan owner. Admin service melakukan login ke system 
untuk mengelola data customer, mendata service, melihat laporan, mengubah profile, dan melakukan logout dari system. Owner dapat mengelola akun pengguna serta dapat melihat laporan service.

Use case diagram Teknisi dengan sistem manajemen service terdapat di Gambar 3.

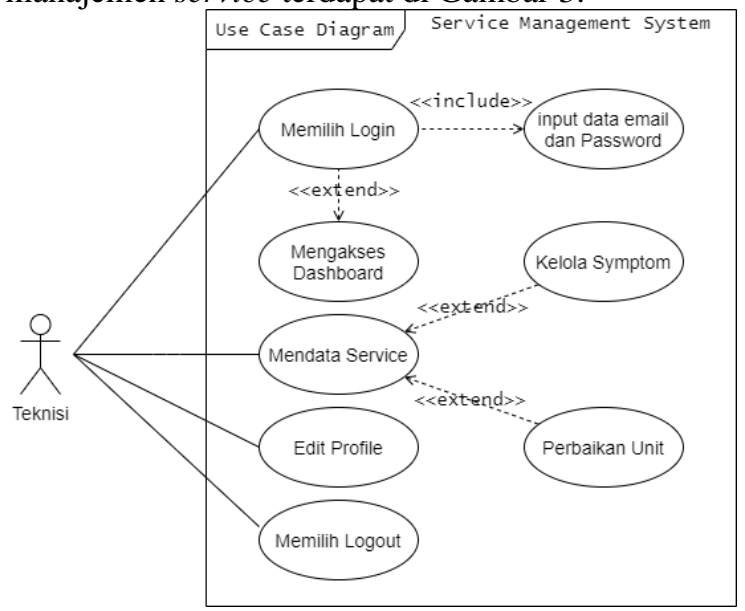

Gambar 3. Use Case Diagram Kelola Symptom
Pada gambar 3 adalah use case diagram kelola symptom yang dilakukan oleh teknisi. Teknisi melakukan login ke system untuk dapat mengelola symptom, perbaikan unit, mengubah profile dan melakukan logout dari system.

B. ERD

tabel-tabel beserta relasinya digambarkan oleh ERD (Entity Relationship Diagram) pada perancangan database terdapat di gambar 4 .

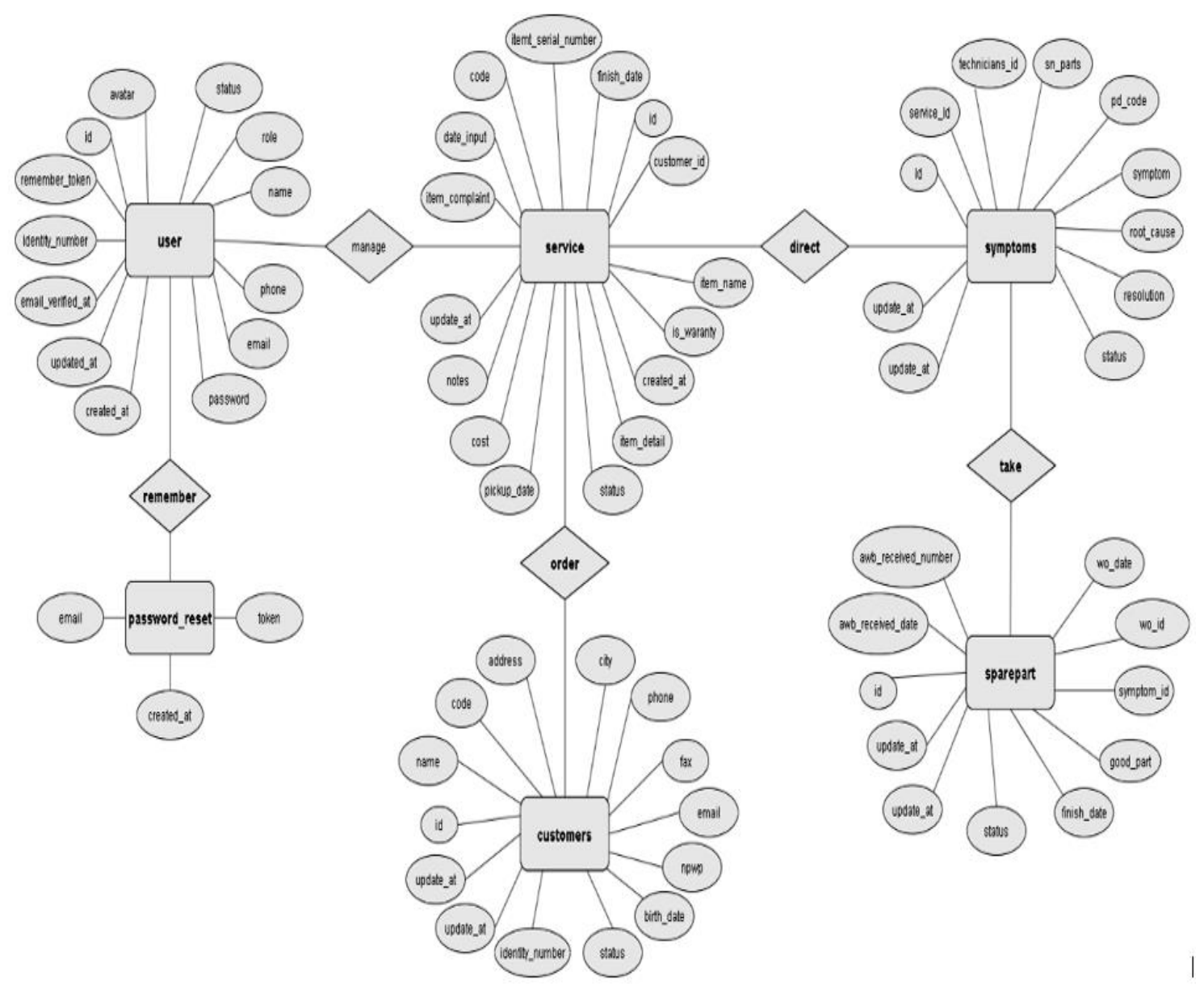

Gambar 4. ERD Service Management System

\section{Tampilan Sistem}

Ditampilkan sistem yang menjadi antarmuka pengguna dari service management system yang dibuat sebagai berikut ini:
1. Tampilan Memilih Login

Tampilan aktivitas pengguna dalam melakukan kegiatan login pada service management system bisa dilihat di Gambar 5. 


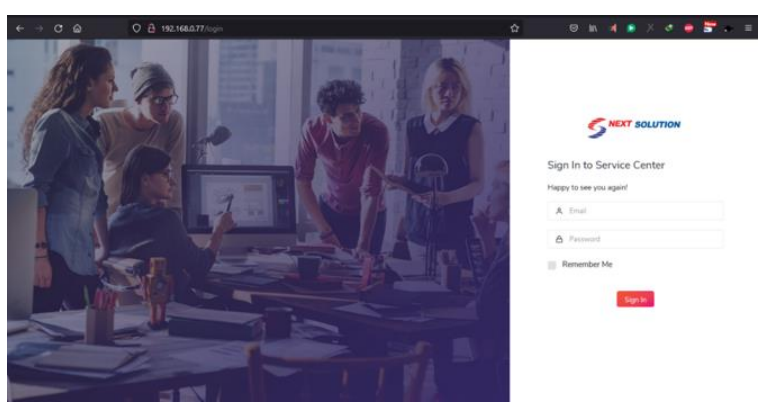

Gambar 5. Tampilan Melakukan Login

2. Tampilan Kelola Customer

Tampilan proses pengguna dalam mengelola data customer pada service management system bisa dilihat di Gambar 6.

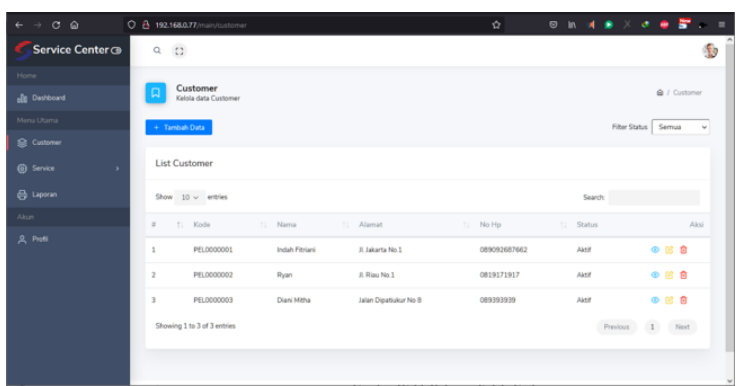

Gambar 6. Tampilan Kelola Customer

3. Tampilan Mendata Service

Tampilan proses pendataan service terdapat 4 pilihan menu berbeda yang dapat diakses oleh admin yang bisa dilihat di Gambar 7 .

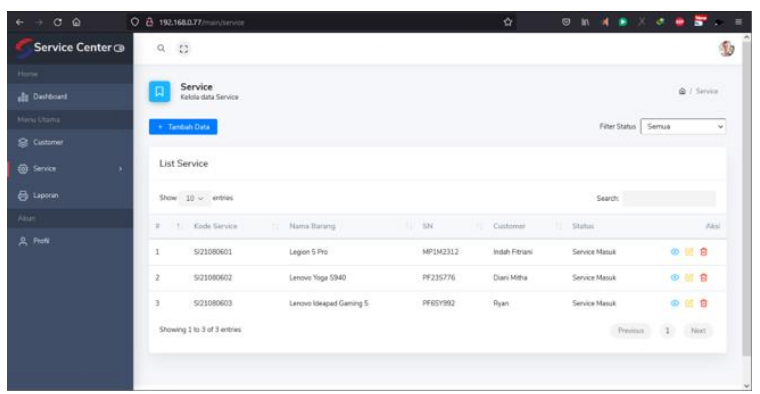

Gambar 7. Tampilan Mendata Service

4. Tampilan Memproses Service

Tampilan dalam memproses service oleh Teknisi terdapat di Gambar 8.

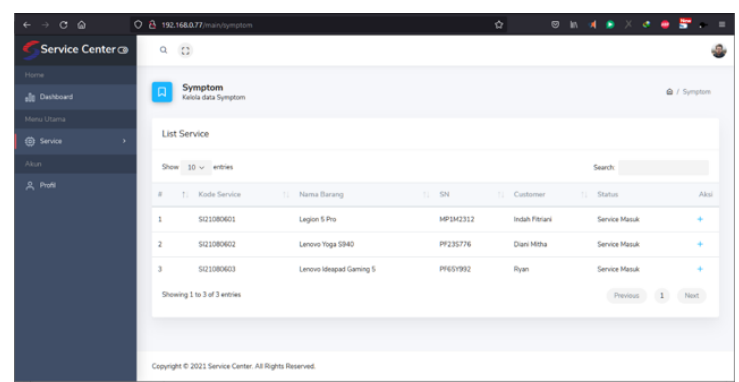

Gambar 8. Tampilan Memproses Service
5. Tampilan Melihat Laporan

Tampilan melihat laporan melalui service management system yang dilakukan oleh Admin dan Owner bisa dilihat di Gambar 9.

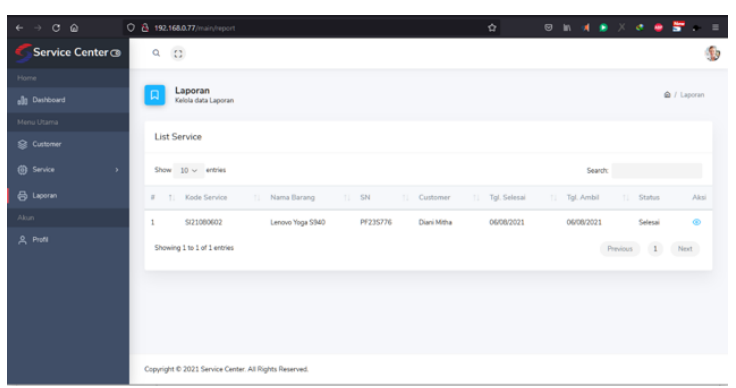

Gambar 9. Tampilan Melihat Laporan

6. Tampilan Mengelola Pengguna

Tampilan pengelolaan data akun pengguna oleh Owner di Gambar 10.

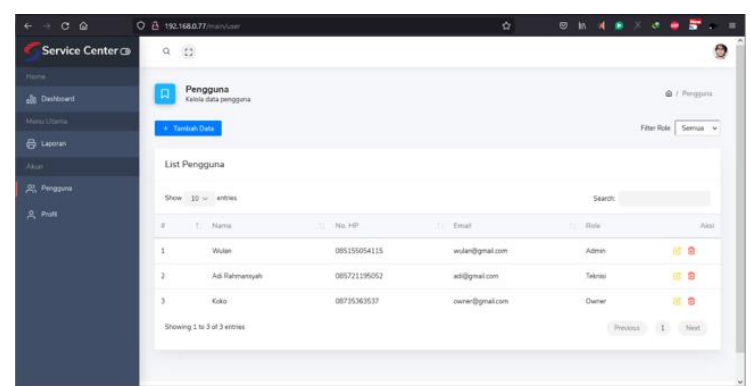

Gambar 10. Tampilan Mengolah Pengguna

7. Tampilan Edit Profile

Proses pengguna dalam melakukan edit data profile semua hak akses pengguna pada service management system bisa dilihat di Gambar 11 .

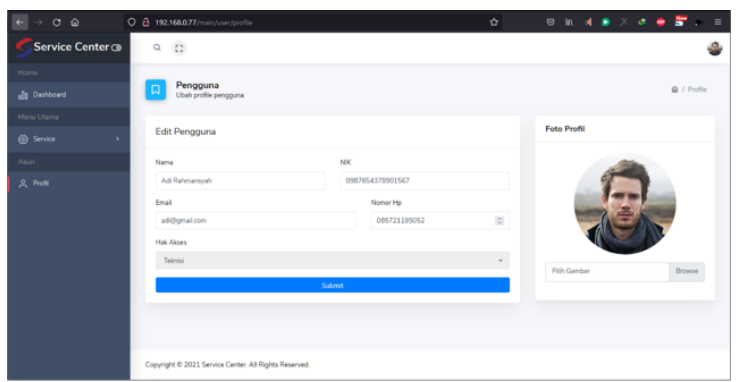

Gambar 11. Tampilan Edit Profile

8. Tampilan Memilih Logout

Proses pengguna dalam melakukan logout oleh semua pengguna pada service management system bisa dilihat di Gambar 12. 


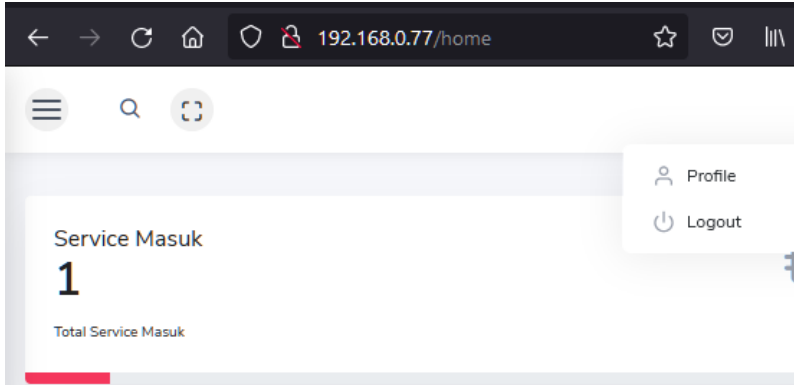

Gambar 12. Tampilan Mengolah Pengguna

\subsection{Penerapan}

Untuk pertama kalinya sistem dibuat di sebuah program kecil yang didefinisikan sebagai unit yang dipecah menjadi Model, View, dan Controller yang menyatu pada tingkat selanjutnya. Unit-unit yang dikembangkan menggunakan framework Laravel. Pada tahap ini, sistem yang telah dirancang atau telah dibuat di terapkan dan difungsikan sehingga sistem ini bisa dijalankan dan didgunakan oleh perushaaan secara optimal dan sesuai dengan kebutuhan yang ada..

\subsection{Tes dan Integrasi}

Tahap integrasi ini, sistem yang telah di terapkan di tes dan diuji dari segala aspek sesuai batasan yang ada untuk mengecek kesalahan yang timbul pada system menggunakan black box testing. fungsi operasional sistem dilakukan pengujian dengan black box testing. Kategori error akan diketahui melalui blackbox testing.

Tabel 1. Hasil Pengujian Black Box Testing Form Data Service

\begin{tabular}{|c|c|c|c|c|}
\hline $\begin{array}{l}\mathbf{N} \\
\mathbf{0}\end{array}$ & $\begin{array}{c}\text { Skenario } \\
\text { Pengujian }\end{array}$ & $\begin{array}{l}\text { Test } \\
\text { Case }\end{array}$ & $\begin{array}{c}\text { Hasil } \\
\text { Penguj } \\
\text { ian }\end{array}$ & $\begin{array}{c}\text { Kesimpu } \\
\text { lan }\end{array}$ \\
\hline 1 & $\begin{array}{l}\text { Mengoson } \\
\text { gkan } \\
\text { semua } \\
\text { isian data } \\
\text { service } \\
\text { pada form } \\
\text { tambah } \\
\text { data, lalu } \\
\text { klik } \\
\text { 'submit'. }\end{array}$ & $\begin{array}{c}\text { Semua } \\
\text { data di } \\
\text { kosong } \\
\text { kan }\end{array}$ & $\begin{array}{c}\text { Sesuai } \\
\text { harapan }\end{array}$ & Valid \\
\hline 2 & $\begin{array}{l}\text { Hanya } \\
\text { mengisi } \\
\text { sebagian } \\
\text { data } \\
\text { service, } \\
\text { lalu klik } \\
\text { tombol } \\
\text { 'submit'. }\end{array}$ & $\begin{array}{l}\text { Sebagia } \\
\text { n data } \\
\text { service } \\
\text { di isi } \\
\text { dengan } \\
\text { sesuai }\end{array}$ & $\begin{array}{c}\text { Sesuai } \\
\text { harapan }\end{array}$ & Valid \\
\hline 3 & $\begin{array}{c}\text { Mengisi } \\
\text { semua data } \\
\text { service lalu } \\
\text { langsung }\end{array}$ & $\begin{array}{c}\text { Semua } \\
\text { form di } \\
\text { isi } \\
\text { dengan }\end{array}$ & $\begin{array}{c}\text { Sesuai } \\
\text { harapan }\end{array}$ & Valid \\
\hline
\end{tabular}

\begin{tabular}{|c|c|c|l|l|}
\hline & $\begin{array}{c}\text { mengklik } \\
\text { tombol } \\
\text { 'submit' }\end{array}$ & $\begin{array}{c}\text { data } \\
\text { service } \\
\text { lengkap }\end{array}$ & & \\
\hline
\end{tabular}

\subsection{Operasi dan Pemeliharaan}

Sistem layanan service laptop yang sudah jadi, dijalankan serta dilakukan pemeliharaan. Pemeliharaan mencakup perbaikan kesalahan yang tidak ditemukan pada langkah sebelumnya. Perbaikan implementasi unit sistem dan peningkatan layanan sistem sebagai kebutuhan baru

\section{KESIMPULAN}

Rancang bangun sistem manajemen service berbasis website pada CV Next Solution merupakan pengembangan bagi kebutuhan pengelolaan data oleh admin, teknisi, hingga owner. Dari hasil penelitian yang dilakukan pada sistem manajemen service berdasarkan permasalhan yang ada dapat disimpulkan bahwa sistem yang telah dirancang oleh penulis memudahkan teknisi dalam melakukan pengecekan history diagnosa perbaikan laptop brand Lenovo, dikarenakan pada sistem tersebut disediakan menu pendataan symptom hingga pencarian history perbaikan laptop dari pelanggan; Sistem manajemen service laptop mempercepat dan mengurangi beban kerja admin service dalam melakukan pendataan barang service dan pelanggan di CV Next Solution. Dengan adanya sistem ini, maka admin service dapat mengakses menu pendataan dan pencarian data barang sesuai dengan status perbaikannya; selain itu dalam menerapkan authorized service center management system berbasis website telah digunakan framework Laravel dan database MySQL. Kedua tools tersebut mampu mengintegrasikan pengelolaan data service yang sesuai dengan keinginan owner maupun kebutuhan di CV Next Solution dengan hasil pengelolaan pendataan dan pengecekan history dari service laptop.

\section{REFERENSI}

Aprilian, L. V., Setyawan, M. Y. H., \& Saputra, M. H. K. (2020). Memahami Metode Omax dan Promethee pada Sistem Pendukung Keputusan. CV. Kreatif Industri Nusantara.

CNN. (2020, October). Pasar Laptop Dunia Tumbuh 12,7 Persen kala Pandemi Covid-19. CNN Indonesia.

Ibrahim, R., \& Susanti, S. (2021). SISTEM INFORMASI TOUR DAN TRAVEL BERBASIS WEBSITE PADA PT. AMADA DESTINASI NUSANTARA. EProsiding Sistem Informasi (POTENSI), 2(1), 20-25.

Junaedi, M. M. H., Susanti, S., \& Mubarok, A. (2020). PENERAPAN FRAMEWORK LARAVEL PADA APLIKASI HRIS (HUMAN RESOURCE INFORMATION 
SYSTEM). Jurnal Responsif: Riset Sains \& Informatika, 2(2), 176-183.

Luthfi, H. D. (2020). Sistem Informasi Pelayanan Jasa Service Laptop Pada Cv. Bismani Solusindo Di Jakarta.

Shalludin, A. (2019). Perancangan Aplikasi Pengolahan Data Service Laptop Pada Syifa Komputer Di Kuala Kapuas. Jurnal Ilmiah Teknologi Informasi Dan Komputer Pranala, 14(1), 25-30.

Susanti, S., Junianto, E., \& Rachman, R. (2017). Implementasi Framework Laravel Pada Aplikasi Pengolah Nilai Akademik Berbasis Web. Jurnal Informatika (JI) UBSI, 4(1). https://doi.org/10.31311/JI.V4I1.1562

Wiguna, W., \& Alawiyah, T. (2019). Sistem Reservasi Paket Wisata Pelayaran Menggunakan Mobile Commerce di Kota Bandung. Jurnal VOI (Voice Of Informatics), 8(2), 49-62.

Wiguna, W., Mauliana, P., \& Permana, A. Y. (2020). Pengembangan E-Helpdesk Support System Berbasis Web di PT Akur Pratama. JURNAL RESPONSIF: Riset Sains \& Informatika, 2(1), 19-29.

Yudhanto, Y., \& Sulandari, W. (2018). Panduan Pengantar Belajar Hardware dan Software: Troubleshooting Laptop. Rumah Studio Indonesia. 